\title{
Transcontinental Contacts: The Marainis' Journey from Italy to Japan
}

\section{Abstract}

In the first half of the 20th century, the Sicilian Princess Topazia Alliata di Salaparuta kept a diary (1938-1941) of her voyage and stay in Japan with her husband, Fosco Maraini, and her three daughters. This journal intime was then passed on to her eldest daughter, Dacia Maraini, the renowned Italian writer, who created a multilayered narrative account entitled La Nave per Kobe: Diari giapponesi di mia madre (The Ship to Kobe: My Mother's Japanese Diaries), which was published in 2001. The female-voiced factual text explores, through two sets of eyes and two people's experiences, the transcontinental contacts from several perspectives. From the physical voyage on board of the Italian ocean liner Conte Verde to their very first days and daily life in Japan - first in Hokkaido and then in Kyoto, before the family's deportation to a concentration camp in Nagoya - Maraini focuses on the subtle plots of interpersonal dynamics, enriching the account with her own childhood memories and her witty remarks generating a meaningful link across time and space. The present paper analyzes the act of crossing physical and figurative borders as a source of reflection in terms of cultural, social, and language exchange. A multidisciplinary approach is used to consider the dialogic nature of the Self and the Other and to explore the identity construction of the two transnational subjects.

Keywords: La nave per Kobe, Maraini, Japanese travel dairy, transcontinental contacts, identity, crossing borders

\section{Introduction}


In the field of psychology, but also in qualitative longitudinal research in general, diaries are valuable, useful yet difficult-to-assess tools that allow regular and deeper insight into the writer's experience. In its purest form, this genre could be a form of self-reflection, or even a therapeutic strategy, whether it is intended to remain private, to have limited circulation or to be shared with a larger audience. In the genre of travel writing, diaries or journals, which mainly differ based on the content and frequency of their entries, constitute a primary form of narration. It has been noticed that female authorship is generally expressed in an epistolary or diary format, suggesting that women's observations were not meant for publication even in the nineteenth century when it became more acceptable (Thompson 180). Thus, the diaries that were kept by the Sicilian Princess Topazia Alliata di Salaparuta (1913-2015), who was an artist and art dealer, between 1938 and 1941, could be considered as a way to record and pass down family legacy rather than a literary work of art. Undoubtedly, then, she cannot be condemned as an embellisher of the truth or a plain liar (Adams 85).

Focusing on the voyage and stay in Japan with her husband, Fosco Maraini, and her three daughters, this mémoire was later given as a present to Dacia Maraini (b. 1936), the eldest daughter and a renown Italian writer, who decided to publish the diaries adding her own reflections and comments; the result is the book entitled La Nave per Kobe: Diari giapponesi di mia madre ( The Ship to Kobe: My Mother's Japanese Diaries, hereinafter abbreviated as NK), which was published in 2001. This double-layered autobiographical narrative - a leap into the Marainis' past, Topazia and Dacia's mother-daughter relationship, and into Dacia Maraini's childhood and very first journey - is significant as a work of literature and as a historical document alike. Due to its peculiar nature, it lies at the intersection of several domains: travel writing, migration studies, and feminist studies, just to mention a few.

Memories, real or imagined, merge with small- and large-scale historical facts; the fragmented narrative and the lack of chronological order of the instances presented by Dacia Maraini create a heterogeneous casket of information describing private, cultural, social, historical, and anthropological changes. To understand how the two authors of this peculiar narrative perceive transcontinental contacts, it is necessary to adopt a multidisciplinary approach, due to the nature of the book, and to reflect on the dialogic nature of the Self and the Other, and in particular, on the 
ways in which a narrative construction is both individual and cultural. It is, hence, crucial to explore the fragmented identity and formation of the 'Self'. Within this framework, personal, gender, and social approaches could be used to unravel this intricate concept.

This paper is divided into four sections: the first concentrates on the interplay between memory, the Self, and diary writing as a narrative in the construction of a transnational subject; the second describes the dynamics of a very uncommon family; the third briefly analyzes the diary from a structural and formal point of view whereas the fourth, through purposive sampling, first explores the voyage from Italy to Japan, and then Japanese life from various perspectives.

\section{Identity (Trans)Formation: Memory, the Self, and Diary Writing}

The role of memory is a leitmotif in Dacia Maraini's production; its function could be summarized as follows: "we are our memories, ... [a]lthough autobiographical memory is important for everyone, for immigrants or those who have lived in many places throughout their lives, memory provides the only sense of continuity"; while places and people constantly change, the ability to remember by binding experiences to a sense of identity is functional in creating this sense of continuity (qtd. in Espín 30). This subsistence is made up of turning points that may be defined as "those episodes in which, as if to underline the power of the agent's intentional states, the narrator attributes a crucial change or stance in the protagonist's story to a belief, a conviction, a thought" (Bruner 31).

Keeping a diary, that is creating a narrative of events and personal remarks whilst travelling, allows Topazia Alliata - in her multiple roles of traveler, emigrant, and storyteller - to create a narration with a specific story and discourse based on specific turning points. These instances become an expression of the Self, one's own culture, and the Other, unveiling "the most intimate aspects of the 'Ego', which emerge due to the confession of, the exchange with, and reciprocity of consciences" (Marchese 187). As a result, the

narrative can be said to provide a portal into two realms: (a) the realm of experience, where speakers lay out how they as individuals experience certain events and confer their subjective 
meaning onto these experiences; and (b) the realm of narrative means (or devices) that are put to use to make (this) sense (Bamberg 77).

A third realm, associated with the idea of a moving or "transnational" identity, should be added: (c) the perception and the representation of the Other based on the exchanges that constantly occur when the 'Ego' crosses national borders. These contacts could be considered the result of the intersection of the micro- and macro-spheres of the Self. By and large, the adjective 'transnational' could be used "for understanding the conduct of social life in a globalizing world" implying an agent-oriented approach and the significance of the transgression of borders (Yeoh et al. 2-3). Several practices stress "the importance of subjective experiences as a basis in the development of knowledge" (Brydon-Miller et al. 44). Along this line of thought, Dacia Maraini claims that diary writing is a "necessity," "it is the need to speak with the Self, to clarify some of the things we struggle to understand: the written word ... is like a map to guide us ...; it provides coordinates that are useful to navigate in life ${ }^{\lceil 1]}$ (Maraini, Amata scrittura 68). Furthermore, the author states that a diary is above all a travel companion sustaining: "as I travel a lot, and almost always alone, the diary keeps me company" (Maraini, Amata scrittura 69).

Two useful concepts could be put forward: Self-making and World-making ${ }^{2]}$ (Bruner 67-78). While continually constructing itself through autobiography, "the constructed Self and its agentive powers become, as it were, the gravitational centre of the world," a process described as "worldmaking" (Bruner 35). Through writing and representation, the Self places itself in the aforementioned state of continuity where the 'Ego' is shaped by dynamics of inclusion and exclusion, oppositions and similarities. Three interrelated dimensions could be analyzed: "the subjective/psychological dimension ...; the personal dimension, or a behavioural and character repertoire that differentiates individuals; and the social dimension, or recognized roles within a community" (qtd. in Côté and Levine 15). Each domain could be further dissected, hence, creating subcategories; for instance, the social aspect could be considered from a community (foreign or own) perspective or from the study of how space and time are depicted, thus focusing on forms of socialization and interactions, as well as the related geography and temporality. Moreover, the personal dimension could be divided into individual, family and homing, that is home-building, whereby home is an affective construct (Hage 102). 


\section{The Marainis}

Princess Topazia Alliata ${ }^{3]}$ was born at the beginning of the 20th century, in 1913, and died in 2015 at the age of 102. She was born in Palermo to Prince Enrico Maria Alliata di Villafranca (1879-1946), Duke of Salaparuta (NK 85) and member of a famous Sicilian aristocratic family of Tuscan origin, and to a former opera singer, Oria Sonia Maria Amelia de Ortuzar Ovalle de Olivares (1892-1981), daughter of a Chilean diplomat. Understandably, Topazia grew up in an aristocratic environment rich in cultural stimuli. However, rebelling to her upbringing, she decided to take a different path by adhering, for instance, to an avant-garde painting movement or falling in love with a Florentine intellectual who was unknown at the time but would later become one of the greatest anthropologists of the 20th century: Fosco Maraini (1912-2004), a passionate mountain climber and traveler.

Both Topazia and Fosco kept diaries and notes of their lives and travels, so extensive autobiographical material is available. Fosco Maraini was also the son of two artists: his father, Antonio Maraini, was a sculptor and his mother of English origins, Yoi Crosse, a writer. The analysis of their language use could be a particularly interesting approach for contact linguistics, as there are several examples of code-switching and code-mixing. Intersentential switching, for instance, can be found in Topazia's diary, as she tends to use English and alternate it with Italian and Japanese in situations of distress (NK 84-85). Furthermore, a unifying factor in their relationship may also be seen in a secret lexicon made up of mixed English and Italian terms, such as the two nicknames Happo e Happa from the English 'happy' (Maraini and Alliata 14).

Dacia Maraini, the first of three children, was born in 1936, so she was only two when her family had to move to Japan. Three years later, Yuki Luisa Maraini (1939-1995) was born in Sapporo and Antonella, known as Toni, was born in Tokyo in 1941. All three daughters developed their artistic talent: Dacia's and Toni's were writing, whereas Yuki's was music.

Fosco Maraini's academic career in Japan started with a scholarship; he first taught in Hokkaido (1938-1941) and then in Kyoto (1941-1943). This is obviously a turning point in the life of the entire family and situates the Marainis within a specific group of travelers and migrants, thus 
implying specific dynamics. This is Dacia Maraini's very first journey. The author's numerous claims about her being a traveler - such as "I was born travelling," "I was bitten by the tarantula of perpetual motion" (Maraini, La seduzione 14) or "I extensively traveled but never as a tourist" (Maraini, Interview), far away then from being "sessile ${ }^{[4]}$ - demonstrate the writer's profound awareness of the practices of traveling and, inevitably, of writing and how these two arts are strictly intertwined.

Mother and daughter could be considered both migrants, as the family settled in Japan for more than one year, and members of the expat community or of a mobile community. Likewise, they fall under the category of "transnational subjects" and agents who negotiate their subjectivities and identities $^{[5]}$ in transnational spaces; indeed "although identities, whether ethnic, racial, social or national, are traditionally said to be 'localised' ... transnational subjects obviously play by a different set of rules since they live in, or connect with, several communities simultaneously" (Yeoh et al. 3). These roles are reflected in language use as a reminder of the fact that "the greatest movements often occur within the self, within the home or within the family, while the phantasm of limitless mobility often rests on the power of border controls and policing of who does and does not belong" (Ahmed et al. 5).

While the Marainis were settling into their Japanese daily life, there was a violent anti-Semitic campaign in Italy in the early months of 1938, which led the fascist regime to promulgate racial laws between September and November. After the Italians signed an armistice with the Allies during World War II, the Japanese authorities separately asked Fosco Maraini and his wife Topazia to sign an act of allegiance to Mussolini's Republic of Salò. They refused and were consequently interned with their three daughters, who were six, four and two years old at that time, in a concentration camp in Nagoya. Dacia has repeatedly referred to this period in terms of "bleeding memory."

\section{The Source Text: Structural and Formal Analysis}

In the volume published by RSC Mondolibri, a substantial part of the pages of the original journal intime kept by princess Alliata is reproduced so that even the non-expert reader can enjoy her 
original handwriting; in some cases, the iconographic material was integrated with photographs that were retrieved from the family archives.

The Marainis' voyage, which was the subject of the first diary (1938-1939), started on 31 October 1938; the family sadly[6] left Italy from Brindisi on board of the transatlantic Conte Verde. Topazia herself traced the itinerary: Port Said, Aden, Bombay, Colombo, Singapore, Manila, Hong Kong, Shanghai, Tokyo, and Sapporo.

The journey, of which Dacia recalls vague fragments, is documented by Topazia while on board of the Conte Verde (Green Count), named in honor of Amadeus VI of Savoy, and then on various steamers and trains. In Foucauldian terms, the heterotopia of the ship, which was the predominant means of transportation to the East, prompts a reflection on the perception of space. The simple metallic shell is transformed into the "greatest reservoir of imagination" since the ship can be considered "a floating fragment of space, a place without place, living for itself, self-delineating and at the same time abandoned at the infinity of the sea" (Foucault 32).

As for the structure, Topazia Alliata's lines, which are written in italics with or without time reference, are interspersed with her eldest daughter's memories and enriched with more general thoughts and considerations spanning from a few lines to entire pages. The resulting narrative memoir develops on multiple layers: as regards time binding past and present in Alliata's two diaries (dated 1938-1939 and 1939-1941) and Maraini's own thoughts as an adult; with reference to space, moving between continents, from Brindisi (Italy) to Sapporo (Japan), or simply all over the world, in Dacia's memories of past times and places; and last but not least, upon traveling physically, geographically, figuratively, and emotionally into the lives and memories of two women who examined, from a privileged standpoint and through two sets of eyes and two separate experiences, transcontinental contacts from several perspectives. Topazia Alliata's diary aligns, on the one hand, with the conventions of the diary genre with discrete entries of various length that are arranged by date reporting what had happened during the day and, on the other hand, with the travel writing genre, as some entries were chronologically collected during the actual trip.

The primary source is substantially an unsolicited self-report and travel log providing detailed and reliable data. As mentioned before, these diaries were not intended for publication or distribution, so it is safe to claim that the information contained therein is as reliable as a personal interpretation 
of subjective reality can be; moreover, it is definitely void of the 'rhetorical tactic' proposed by Edward Said in Orientalism. Spatial linearity is in sharp contrast with temporal deformations.

\section{Interpreting Transnational Contacts}

\subsection{The voyage from Italy to Japan}

The first volume of Alliata's diary (October 31, 1938-June 30, 1939) follows the traditional linear presentation of events from the actual journey by sea to the first days in Japan in December. This linearity is undermined by Dacia Maraini's reflections, which force the readers to navigate along different trains of thought.

In the first section of this first diary, Alliata rarely openly expresses her feelings; she tends to concentrate on her daughter and her upbringing. The entries are a repetition of a specific pattern that had been formed by the city and whether or not the family or one of its members went ashore (e.g. "Aden - I disembarked. D remains on board with Fosco"; "Bombay - we arrived at about 5. We can disembark only around 11. D. fell asleep - left in the care of the maid. We disembark" NK17-18). These are short notes, jotted down almost as if in a rush ${ }^{[7]}$, with the purpose of remembering the itinerary rather than pondering the implications entailed by this journey.

As mentioned, most of the entries focus on Dacia (referred to as D. or using the diminutive 'Daciuzza') and her life on board. Therefore, the social sphere is mainly represented here by the people Dacia interacts with. Nevertheless, overall, this component is quite scarce. Alliata's pages are almost void of descriptions of the Other. On board the Conte Verde, the Marainis meet a priest, Padre Rovelli: "There is a very nice missionary on board - Father Rovelli on his way to China. He easily wins D. over by always carrying some candy in his pocket for her" (NK13). This is one of the two instances in which a person's proper name is reported. Commenting on this encounter, Maraini does not remember this particular person but she reflects on the other missionaries she has met in the course of her life, especially in Africa. Maraini's ironic nature strongly emerges: "I can say l've fallen in love with some white beards of celestial gravity, while on other occasions I happened to come across small, prelatic hands, greedy for pleasure and money" (NK 14). Such a direct and perhaps harsh statement is not surprising as Maraini's frankness, even on delicate subjects, is a 
classic trait of her entire literary production. The second instance regards Dacia's friend, Lilongo Tam, who disembarks with her family in Hong Kong. No previous or further information is given about this girl either by Dacia or Alliata. However, this specific entry is functional for Dacia as she delves into her private life by recalling another trip to the same location with "Alberto" (Moravia, the Italian journalist and novelist) during which they came across two chimpanzees. A picture taken with a chimpanzee in her arms reminds her of the child she lost during the seventh month of pregnancy. With this loss, she "loses any affection for a family" (NK33). Despite the seriousness and sadness of the memory, these few lines are dry, with no display of any melodramatic grieving. Moreover, a second trip to Hong Kong during a layover while travelling to Australia spurs a consideration on the disposition of the local people who resume their daily life as usual after a terrible hurricane has swept away everything on its path. Patience, a strong temperament and perseverance are the features that are associated with the locals.

In general, their contacts with the foreign community, at this stage of the journey, seem quite superficial. In Alliata's entries, the members of this community are generic individuals: "waiters and maids" or "Several invitations - a lot of things to do and people to see" (NK 35). Dacia wonders who these generic people are and, as they had just arrived ashore, how many people they could have met. It is possible to think that the acquaintances on board and their contacts ashore had been much more numerous than those reported on paper. In addition, it could also imply the existence of an intertwined network of transient travelling or expat communities. While in a hotel in Shanghai (November 24) the Marainis needed a nanny for Dacia while they were socially engaged. Another new figure is introduced, the "hama," whom Alliata describes, her attire first ("dark blue trousers, white apron, shiny black hair pulled tight and tied tight behind") and some physical traits ("many golden teeth and a golden complexion") and then, relying on her sense of smell, she comments: "She has her own peculiar smel[ ${ }^{[3]}$ - strong - but not dirty and not unpleasant" (NK 35). Maraini herself reflects on this attitude of her mother's: she underlines her mother's "security of [her social] class," as if "it were a natural attribute to the family." This approach to the "lower" class is deemed improper by Dacia, who considers it a generational clash.

While in China, Alliata's reading of space is mainly horizontal and describes the populated streets, the bicycles and ricsciò, and the fear of infection. Nevertheless, Maraini, who was in China in 2000, 
mixes the spatial levels, from "monsters of cement and glass" that conquer the sky for a vertical reading of space, to the cars that have replaced the bicycles within a horizontal perspective. A constant is represented by the rickshaws, which are the "testimony of past China, now gone." The human presence is latent. These are spaces of social interaction, yet the figures that populate them remain indistinct.

The same approach is applied to the Japanese, thus shifting the high/low spatial relationship into the sphere of social relations. Alliata wrote: "All the Japanese are very kind - even too much so to the children and D., it seems to me, in a special way. It is strange to feel looked at so much" (NK 44). The traveler develops a deeper awareness towards the Other. A reversed sense of curiosity transforms the Observer into the Observed. The perception of the Self and the Other plays a key role in the interpersonal exchanges. The metaphor used to best portray this situation is quite effective: “The crowded 'Ginza' Avenue is D.'s battlefield; she acts as if it were a watershed between the skirts (kimono!) and the clogs in order to collect a trail of 'kawai né?' (cute, isn't she?). It is almost embarrassing." (NK 44) Historically, it is an obvious indication that the presence of foreigners in the area was not very common back then. Moreover, Alliata reiterates that sense of superiority that emerged before: "Everyone smiles at me and I feel like those royals who walk between two rows of citizens who have to smile and bow their heads" (NK 44-45). Lexically, one could identify a struggle between poles and a blatant sense of superiority, which in this case could become emblematic of a tension between two different systems, the East and the West.

\subsection{Settling in: Life in Japan}

On December 15 in Sapporo, Japan, it copiously snowed. Dacia still drew the attention of the local people who seemed to be polite and different from those of Tokyo (NK 47). The elements of this entry are representative: the weather, the focus on the daughter, and a quick glance at the locals. Alliata and Dacia roam the social grid interfacing with the anthropological subjects: as observers, and therefore active members in the exchange, they expand their knowledge by experiencing the Other in its environment and, simultaneously, mold their Selves.

Alliata focuses on Dacia's growth in the first diary, and in the second her identity as a mother remains prominent, so the reader gets to know more about her through her relationship with her 
daughters. All the same, the diary is used to keep note of the children's health, feelings, habits, achievements, and sisterly bond; as a result, there seems to be little room to dwell upon her journey into mental, physical, and emotional transformations.

The linguistic aspect is of particular interest here. As previously mentioned, Topazia and Fosco spoke both Italian and English; the adoption of different linguistic codes is inevitable for the three daughters who were born and raised in a multicultural and multilingual environment. This emphasizes their level of integration in, and awareness of, the new community that the Marainis have adopted as their own. The phenomenon reaches such a level that Maraini claims: "I speak Japanese better than Italian. Isn't this integration! It is not a duty; it is a pleasure of the mind and of the body. It's just difficult to establish the limits between one culture and the other" (NK 133). While crossing cultural and linguistic borders, the subject risks losing the connections on which the Self is founded.

On the one hand, Fosco Maraini is a fervent supporter of the local culture (e.g. the Ainu ceremony to "christen" Luisa Yuki [NK 77]); on the other hand, Topazia Alliata tries to recreate "home away from home." These two opposing intentions give rise to a new, hybrid set of traditions. This also allows the daughters to develop a new way of interpreting the world. As her husband is quite often absent from home, Topazia has to manage the family. She balances their Italianness (decorating the Christmas tree, exchanging small welcome presents with their new neighbors), their becoming Japanese (drinking the ritual tea, learning the language, wearing local clothing), and their being part of an expat community while constructing their temporary home. Alliata wrote:

D. has already begun to speak the dialect of Kyoto (aspired like the Florentine one). The only disadvantage of this house - the 'tonari', the neighbors with their five dirty, rude children with whom D. always wants to play. It is a struggle to keep her at home with these Japanese customs, and the children always come over (NK 126).

After this short entry, Maraini recalls the scents and the sounds of the past and asks herself "What is diversity, then, a feeling? A wall of meat? A concoction of detectable smells? Even today, I do not know" (NK 127). The Marainis felt different, they stood out as different. This, then, could be considered a peculiarity of a transnational subject who plays by a different set of rules and places 
him/herself on a different level of action because the values that are used to interpret the world are constantly changing; they are the outcome of the continuous exchanges to which the Self is subjected.

The alternation of languages and lexical choices hint to the various phases of this process of identity (trans)formation. For instance, Fosco Maraini wanted to name their third daughter "Akiko," which means chrysanthemum, but "the fascist regime forbade the use of foreign names, so they ended up naming her 'Antonella', 'Toni' in short” (NK 168). Dacia Maraini observes: "It was certainly part of my father's anthropological strategy: if she was born in Japan, she would be part Japanese, and the name will establish a geographical reality that may not agree with the reality of the registry but will reveal a cultural belonging" (NK 169). This attempt to reproduce this "geographical reality" suggests a clear connection between space, culture, and identity. It is through language use that the subject identifies and locates him/herself in society.

In addition, this simple example shows how the rituals of the exotic Otherness are overturned. In Japan, the chrysanthemum is considered a symbol of longevity, whereas in Italy it is the flower of the dead. Dacia Maraini wrote: "the chrysanthemum, kiku, evokes the word kiku-ri, which means listening to the truth by homophony, from which Kukuri, the name of a primordial kami, derives (NK 169). The term 'kami' refers to deity(ies), god(s), goddess(es), a supreme being, a principle and anything that can be worshipped (Holtom 1).

Finally, the streets and their crowds are still the social spaces of interaction, along with the hospital and some temples, a shopping center, and Japanese homes. These locations are used by Dacia Maraini to reflect upon a wide range of topics, such as religious and cultural differences. Nevertheless, these are all anthropological spaces, and sometimes anthropological places, of transience, as Marc Augé defined them in Non-Places, where human beings mainly remain anonymous.

\section{Conclusions}

Topazia Alliata and Dacia Maraini crossed linguistic, cultural, and social borders. They could be considered travelers, migrants, and, ultimately, transnational subjects. It is within this framework 
that they work on their Selves while exploring the Other. The diary genre takes on several functions: it is (i) a travel log initially and then a note book, (ii) a legacy keeper, (iii) a source of inspiration, (iv) a psychological map for the Self, and, for Maraini, (v) a form of self-reflection. Narrative becomes functional in reviving memory and supporting a sense of continuity while anthropological spaces, places, and subjects keep changing. La Nave per Kobe is a portal into three realms: the agent's experiences, narration, and the representation of the Other. This text emphasizes the dialogic nature of the two processes of Self-making and World-making.

The linearity of Alliata's pages merges with Maraini's stream of thoughts, thus binding the temporal and spatial dimensions. The fragmented mind is mirrored in narrative fragmentation. The high/low spatial relationship is directly reflected onto Alliata's social contacts. Both authors are strong female characters: despite re-proposing class differences that are anchored in a typical, seemingly foregone societal system, Alliata's ability to adapt to a different geography and cultural area is noteworthy while Maraini, who often prefers a horizontal reading of space and the Other, reflects on herself and her experiences as a child and as an adult in a witty way. Growing up in Japan allowed her to develop a different set of values and criteria with which to interpret the world. The community and interactions that characterize their social life are simply outlined; the people who populate their lives often remain indistinct entities. Maraini certainly mentions more people by name or level of relationship. Her reflections and remarks are definitely the product of a multicultural and multilingual mind. Within these pages of the double-layered autobiographical narrative, the mother-daughter relationship is based on profound respect and admiration. These feelings are typical of Maraini's prose, which often develops around the story of her family members. Identity formation also revolves around language use, for, as mentioned, code-switching and code-mixing are features of the deeper processes of adaptation and integration.

\section{Works Cited}

Adams, Percy G. Travel Literature and the Evolution of the Novel. The University Press of Kentucky, 2015.

Ahmed Sara, et al., eds. 2003. Uprootings/Regroundings: Questions of Home and Migration. Oxford/NY: Berg, 2003. 
Augé, Marc. Non-Places: An Introduction to Anthropology of Supermodernity. Verso, 1995.

Bamberg, Michael. "Narrative Analysis." APA Handbook of Research Methods in Psychology, vol.

2: Quantitative, Qualitative, Neuropsychological, and Biological, edited by Harris Cooper, et al., The American Psychological Association, 2012, pp. 77-94.

Bruner, Jerome. "Self-making and World-making." Narrative and Identity: Studies in Autobiography, Self and Culture, edited by Jens Brockmeier and Donal Carbaugh, John Benjamins Publishing Co., 2001, pp. 25-37.

Brydon-Miller, Mary, et al., eds. Traveling Companions: Feminism, Teaching, and Action Research. Greenwood Publishing Group, 2004.

Côté, James E., and Charles G. Levine. Identity Formation, Agency, and Culture: A Social Psychological Synthesis. Lawrence Erlbaum Associates Publishers, 2002.

Doloughan, Fiona J. "Narratives of Travel and the Travelling Concept of Narrative: Genre Blending and the Art of Transformation." Studies across Disciplines in the Humanities and Social Sciences, vol. 1 The Travelling Concept of Narrative. Helsinki Collegium for Advanced Studies, 2006, pp. 134-44.

Espín, Oliva M. “A Geography of Memory: A Psychology of Place.” Gendered Journeys: Women, Migration and Feminist Psychology, edited by Oliva M. Espín and A. Dottolo, Palgrave MacMillan, 2015, pp. 29-53.

Foucault, Michel. Spazi Altri. I Luoghi delle Eterotopie. Translated by T. Villani, Mimesis Edizioni, 2011.

Hage, Ghassan. "At Home in the Entrails of the West: Multiculturalism, Ethnic Food and Migrant Home-building.' Home/World: Space, Community and Marginality in Sydney's West, edited by Helen Grace, et al., Pluto Press, 1997, pp. 99-153.

Holtom, D.C. "The Meaning of Kami. Chapter I. Japanese Derivations." Monumenta Nipponica, vol. 3, no. 1, 1940, pp. 1-27.

Leed, Eric J. The Mind of the Traveler: From Gilgamesh to Global Tourism. Basic Books, 1991. 
Maraini, Dacia. Amata scrittura. Laboratorio di analisi, letture, proposte, conversazioni. Kindle Ed., Bur, 2012.

Maraini, Dacia. La nave per Kobe: Diari giapponesi di mia madre. RSC Libri, 2001.

Maraini, Dacia. La seduzione dell'altrove. Rizzoli, 2010.

Maraini, Dacia. Interview. "Dacia Maraini, viaggiare non da turista." Rai Letteratura, www.raicultura.it/letteratura/articoli/2018/12/Dacia-Maraini-viaggiare-non-da-turista-deaaae3796c7-47aa-ab2c-94983cb1ab71.html. Accessed 5 Apr. 2020.

Maraini, Toni. Ricordi d'arte e prigionia di Topazia Alliata. Sellerio, 2003.

Maraini, Fosco, and Topazia Alliata. Love Holidays. Quaderni d'amore e di viaggi. Rizzoli, 2014. Marchese, Angelo. L'officina del racconto. Oscar Mondadori, 1983.

Ruta, Anna M. Topazia Alliata: una vita nel segno dell'arte. Edizioni Kalòs, 2010.

Said, Edward W. Orientalism. Penguin Books, 2006.

Thompson, Carl. Travel Writing. Routledge, 2011.

Yeoh, Brenda, et al., eds. Approaching Transnationalism: Studies on Transnational Societies, Multicultural Contacts, and Imaginings of Home. Springer Media, 2003. 
[1] All the passages of the book are translated from Italian into English by the author of the present paper.

[2] Bruner concludes that the making of the Self and of the World depends on the symbolic system in which it is constructed (36). Doloughan maintains that "[i]n pointing to the opportunities and constraints of particular symbolic systems, Bruner is acknowledging narrative (self-)construction through the medium of language, in either verbal or written mode, as a culturally-mediated activity reflecting sets of (expressive and interpretive) norms and conventions as well as opportunities for shaping and presenting aspects of agency" (135).

[3] See: T. Maraini; Maraini and Alliata; Ruta.

[4] In zoological terms the adjective 'sessile' refers to the idea of being 'permanently planted', thus, remaining in a set place; Leed puts this notion forward in contrast to the male logic of mobility (171).

[5] 'Subjectivity' relates to the individual's position in relation to power whereas 'identity' emphasizes the process of construction of the Self.

[6] "The parting is sad, and we are all very tired. Dacia didn't get enough sleep and is difficult and nervous." (NK 10)

[7] Maraini confirms: "una mano frettolosa la sua" (a hasty hand) (NK 29).

[8] Smell, after sight, is a fundamental sense for analyzing the surrounding world. Other authors, such as Pasolini in India or Terzani in Asia, have described the smells of the places they visited. It is one of the aspects on which memory is based to evaluate and recollect a specific experience.

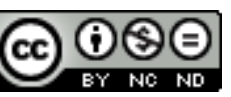

Creative Commons Attribution-NonCommercial-NoDerivatives 4.0 International License 